\title{
Screening in Psycho-oncology---Need for Psycho-oncological and Psycho-social Care of Oncological Patients: A Pilot Survey Using the Hornheider Questionnaire
}

\author{
Petra Sumnitsch ${ }^{1,2, *}$, Bernd L. Hartmann${ }^{1}$, Daniela Zanolin ${ }^{2,3}$, Christoph H. Saely ${ }^{1,2,3}$, Alois Lang ${ }^{1,3}$ \\ ${ }^{1}$ Department of Internal Medicine and Cardiology, Academic Teaching Hospital, Austria \\ ${ }^{2}$ Private University of Principality, Liechtenstein \\ ${ }^{3}$ Vorarlberg Institute for Vascular Investigation and Treatment (VIVIT), Austria
}

Copyright $₫ 2017$ by authors, all rights reserved. Authors agree that this article remains permanently open access under the terms of the Creative Commons Attribution License 4.0 International License

\begin{abstract}
Aim/object: The aim of this survey was to identify psycho-oncological and psycho-social need in the routine patient care of oncological patients. Material and Methods: A total of 200 oncological patients underwent the paper-based Hornheider questionnaire, a validated instrument to identify the need of psycho-oncological and psycho-social care at first contact. Hornheider sum-scores $\geq 4$ were considered to indicate psycho-oncological and psycho-social need. Results: Overall, 149 (75\%; 68 women and 81 men, $74 \geq 65$ and $75<65$ years) questionnaires were correctly filled out and returned. Hornheider sum-scores were $\geq 4$ in 47 patients, i.e. in 31,7\%. Psycho-oncological and psycho-social need did not differ significantly between women and men $(57,5 \%$ vs. $42,5 \% ; p=0,732)$ but was significantly higher in patients $<65$ years than in those $\geq 65$ years ( $66 \%$ vs. $34 \%$; $p=0,002)$. Discussion: The results of this pilot project show that a high proportion of oncological patients are in need of psycho-oncological and psycho-social support; this in particular holds true for younger patients.
\end{abstract}

Keywords Cancer, Psycho-oncology, Psychosocial Support, Hornheider-screening, Clinical Day

\section{Introduction and Theoretical Background}

After cardiovascular disease, cancer is the second most common medical condition. According to the Austrian Cancer Registry, the annual morbidity rate of cancer in Austria totals around 39,000 patients, of which 18,800 are women and over 20,200 are men [1]. Cancer causes approximately a quarter of annual deaths. While the incidence of new cases and mortality tends to decrease, the prevalence is increasing.
Diagnosis and treatment are a heavy burden for cancer patients. Approximately one third to half of all patients suffering from cancer report severe changes in their lives in addition to increasing psychological strain, including debilitating, clinically relevant symptoms [2-6].

Psycho-oncology and its interdisciplinary, patient-oriented treatment approach in medical care and the cooperation with various occupational groups, e.g. social-service work or pastoral care, supports and aids cancer patients during the stages of prevention, diagnosis, therapy, rehabilitation and follow-up treatment $[7,8]$. The efficiency of psycho-oncological services such as consultation, musical therapy, several relaxation methods or psychopharmalogical treatment can be seen in a significantly positive support in coping with cancer and an improvement in the quality of life of patients [9]. The results of studies investigating the effect of psycho-oncological interventions on the somatic disease progression are contradictory $[10,11]$. The four main functions of psycho-oncology are support in illness processing, strengthening the resources, the preservation/improvement of quality of living as well as the detection and treatment of psychological stress reactions of patients, relatives and members of the treatment team $[12,13]$.

Numerous studies show the improvement in coping with the progression of the disease $[14,15]$.

Psycho-oncological support services are not being provided and/or not utilized enough in many places. For the requirements analysis it is therefore necessary to apply psycho-oncological screenings [5,16,17].

An early diagnosis and the availability of preventative care are sensible in order to avoid premature decompensation processes within the family. It is worth mentioning that hardly any oncological patients prematurely and directly take advantage of according offers of support $[14,18]$.

Various reasons can be found for this, such as the lack of 
personnel resources and funding [15], a lack of requests by patients concerned, as well as insufficient communication among doctors, caregivers and affected patients [14,19].

In specialist literature five useful screening methods are frequently mentioned $[5,15,16,17,19,20]$ :

- Hornheider Questionnaire (HSI) [14,16,21,22]

- Hospitality Anxiety and Depression Scale (HADS) [14,16]

- Questionnaire on the burden of cancer patients (FBK) [14]

- Psychooncological Basis Documentation (BADO) [14]

- Distress-Thermometer (NCCN) [14,5]

Consequently, there is a demand for a quick, practicable and easy screening method which is applicable in daily medical routines [23]. During inpatient treatment the demand is hardly mentioned or detected by attending physicians. In clinical routine offering resource-conserving diagnostics with a quick identification of patients in need of care is a necessary instrument for physicians, caregivers and psychosocial staff members. It should be free of psychiatric technical terms, easily applicable in clinical routine, with a high accuracy and a quick analysis in order to ensure a prompt assignment to psycho-oncological and psychosocial supply offer.

Little data is available on the demand for psycho-oncological support. One study relays that 25 and $40 \%$ [14] of all patients are in need of psycho-oncological and psychosocial support.

\section{Research Objective, Research Question, Hypothesis}

The aim is to conduct a research on the detection of the need of care of cancer patients. We regard in psycho-oncological, psychosocial and oncological situation This was a patient group in a clinic with oncological focus.

\section{Material and Methods}

\section{Sample and Study Design}

In the period from July 1st, 2012 to December 31st, 2012, 200 Patients $>18$ years with various tumor entities of the oncologic ward of the Department of Internal Medicine and Cardiology in Feldkirch (LKHF), an Austrian Academic Hospital, which is focusing on the federal state of Vorarlberg (400,000 inhabitants) were invited to participate in a pilot project in the course of their psycho-oncological routine screening.

The patients had tumors and were undergoing chemotherapy. The exclusion criteria were missing consent, a severely reduced overall condition or cognitive limitations of patients which thus made an independent processing of the survey impossible.

\section{Questionnaire}

Name, age, residence, tumor entity were inquired. Subsequently the Hornheider Questionnaire by Strittmatter, Mawick, Tilkorn [20] was handed out (figure 1), which includes seven general questions. It was utilized as a paper-pencil-test that the cancer patients could fill out themselves.

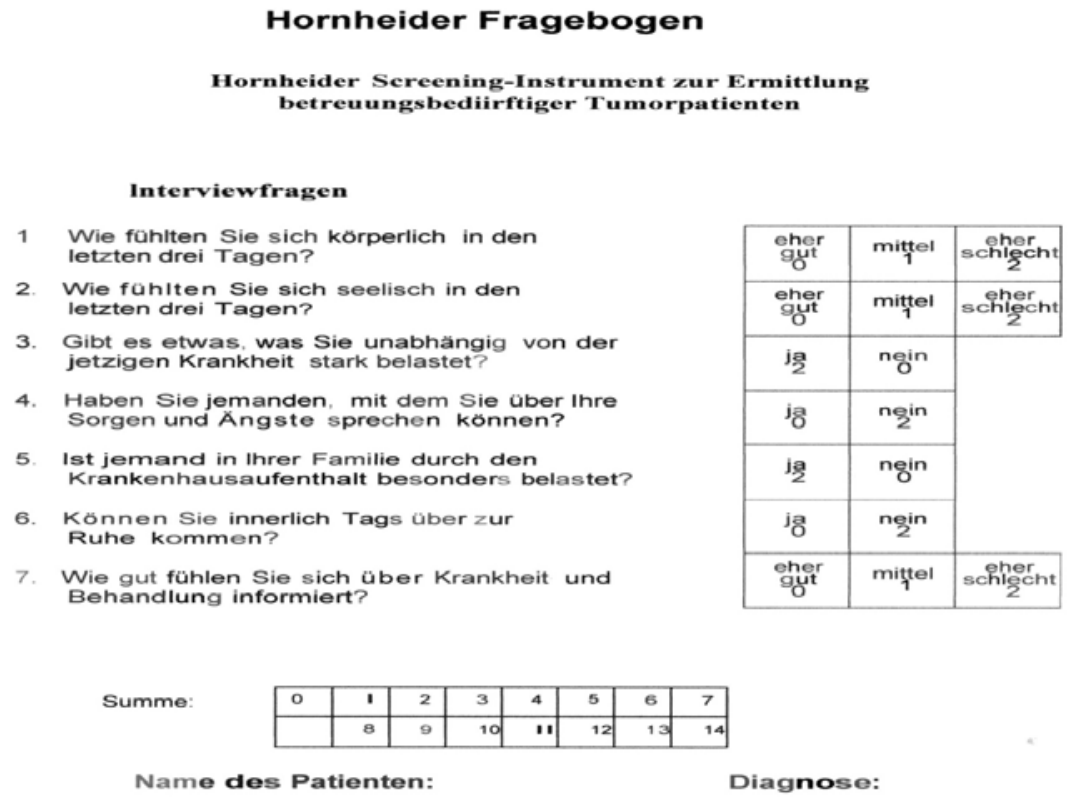

Datum:

Patient(in) betreuungsbedürftig

Figure 1. Stress Items from the Hornheider Questionnaire 


\section{Statistical Analysis}

The individual questionnaires' data was calculated via simple addition of the item-figures. A sum-score $\geq 4$ indicates a psycho-oncological/psycho-social need for care. The demographic data has been depicted descriptively. Differences were reviewed regarding their significance consulting the Chi-Quadrat-Test and the Mann-Whitney-U-Test. All statistical analysis was conducted using the software IBM SPSS Statistics 22, 2013 for Windows.

\section{Ethics Vote}

This pilot study was submitted to the ethical review committee of the federal state of Vorarlberg for examination. The ethical review committee considered the presented project. They noted that there is no need and/or responsibility of the curators of the ethics committee regarding the review of this project.

\section{Results}

In total 200 patients were given the Hornheider Questionnaire; 167 participated in the survey, 149 correctly filled it out and returned it, of which 68(46\%) were female, 81(51\%) male and 9(6\%) unspecified. The average age was 62,9 years, the youngest patient was 19 , the oldest 89 years.

Figure 2 shows the psycho-oncological load profile within the surveyed patient cohort. A sum-score $\geq 4$ in the Hornheider Questionnaire was reached by $47(31,7 \%)$ of the affected patient group (42,6\% men and 57,4\% women; $\mathrm{p}=0,732$ ). Figures 3 and 4 show the results of the Hornheider Questionnaires divided according to gender and age groups. While no significant difference could be seen regarding the gender, we could observe a substantial difference $(\mathrm{p}=0,002)$ in the need for care between $<65$-year-olds $(62,2 \%)$ and $\geq 65$-year-olds (37,5\%).

Table 1. Study Participants' Characteristics in consideration of Gender

\begin{tabular}{l||cc}
\multicolumn{1}{c||}{$\begin{array}{c}\text { Study Participants } \\
\text { (n=149) }\end{array}$} & $\begin{array}{c}\text { Men } \\
\text { (n=68) }\end{array}$ & $\begin{array}{c}\text { Women } \\
\text { (n=81) }\end{array}$ \\
\hline \hline & $63 \pm 12$ & $62 \pm 14$ \\
Age (Years) & 33.8 & 9.9 \\
Gastrointestinal Tumors (\%) & 44.1 & 21,0 \\
Haemato-oncolog. Tumors (\%) & 0 & 43,2 \\
Mamma Tumors(\%) & 22.1 & 25.9 \\
Other Tumors (\%) & &
\end{tabular}

Table 2. Study Participants' Characteristics in consideration of Age

\begin{tabular}{|c|c|c|}
\hline $\begin{array}{l}\text { Study Participants } \\
\qquad(\mathrm{n}=149)\end{array}$ & $\begin{array}{c}\text { Age Group 1 } \\
\text { “<65 years” } \\
(n=75)\end{array}$ & $\begin{array}{c}\text { Age Group } 2 \\
\text { “ } \geq 65 \text { years” } \\
(n=74)\end{array}$ \\
\hline Age (years) & $52 \pm 9$ & $73 \pm 5$ \\
\hline $\begin{array}{c}\text { Men (\%) } \\
\text { Gastrointestinal Tumors (\%) }\end{array}$ & $\begin{array}{c}21,5 \% \\
58,1 \\
\end{array}$ & $\begin{array}{c}24,2 \% \\
41,9 \\
\end{array}$ \\
\hline $\begin{array}{c}\text { Haemato-oncolog. Tumors } \\
(\%)\end{array}$ & 36,2 & 63,8 \\
\hline Mamma Tumors (\%) & 71,4 & 28,6 \\
\hline Other Tumors (\%) & 41,7 & 58,3 \\
\hline
\end{tabular}

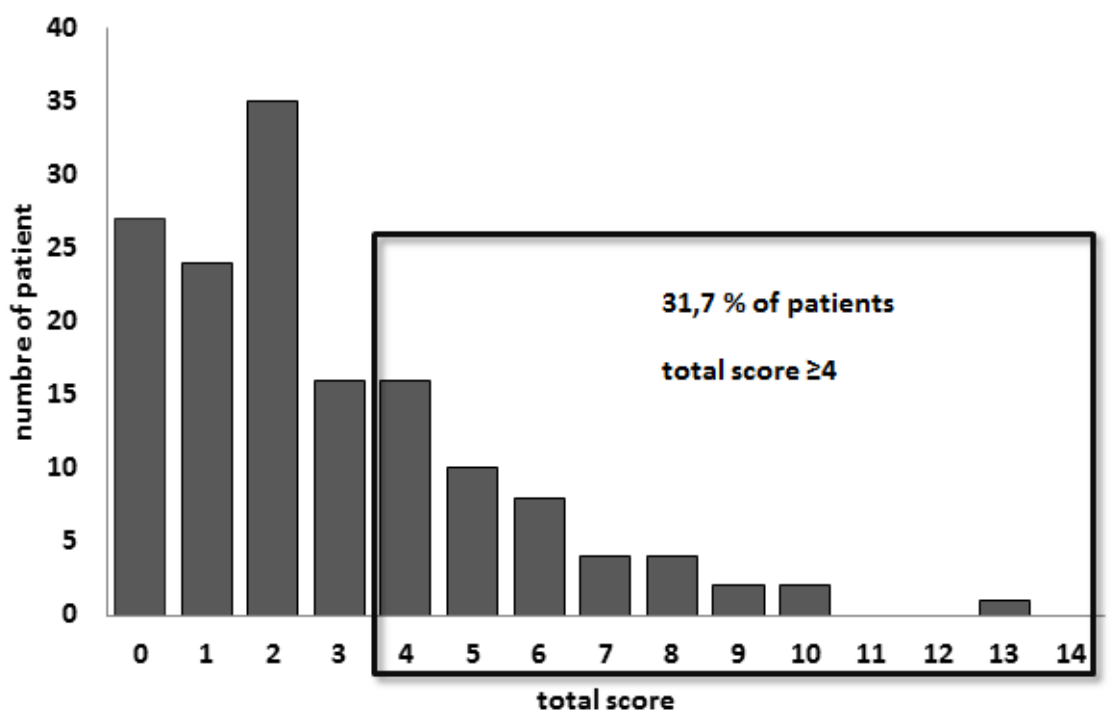

Figure 2. Load Profile of the Sample 


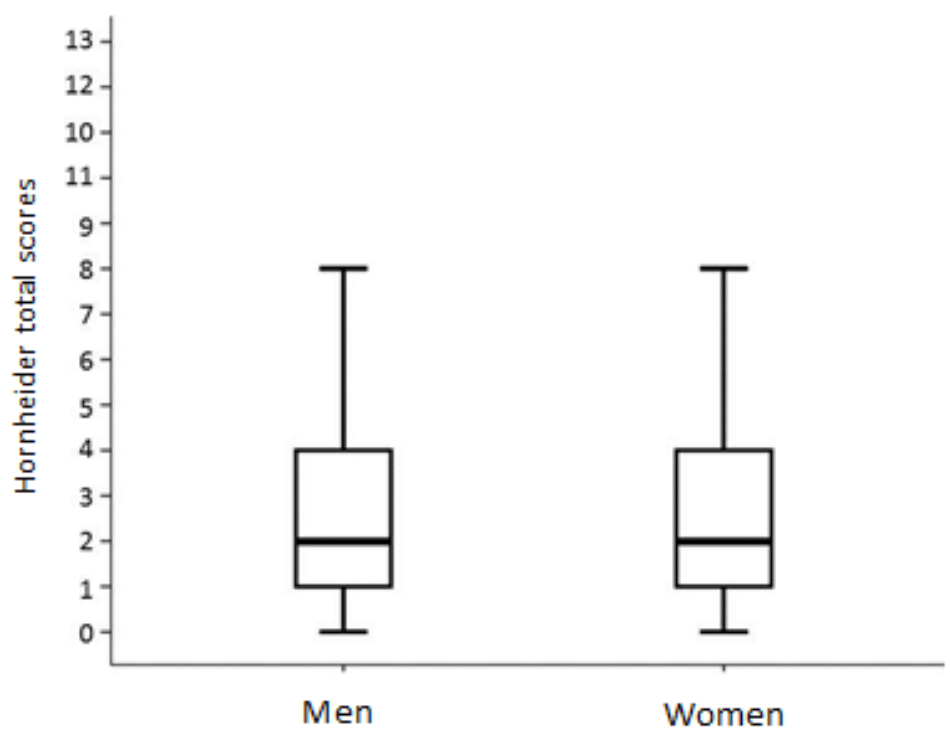

$p=0,732$

Figure 3. Psycho-oncological need for care by women and men

\section{Gender Effects}

No relevant difference between men and women could be detected in the return rate of the questionnaires.

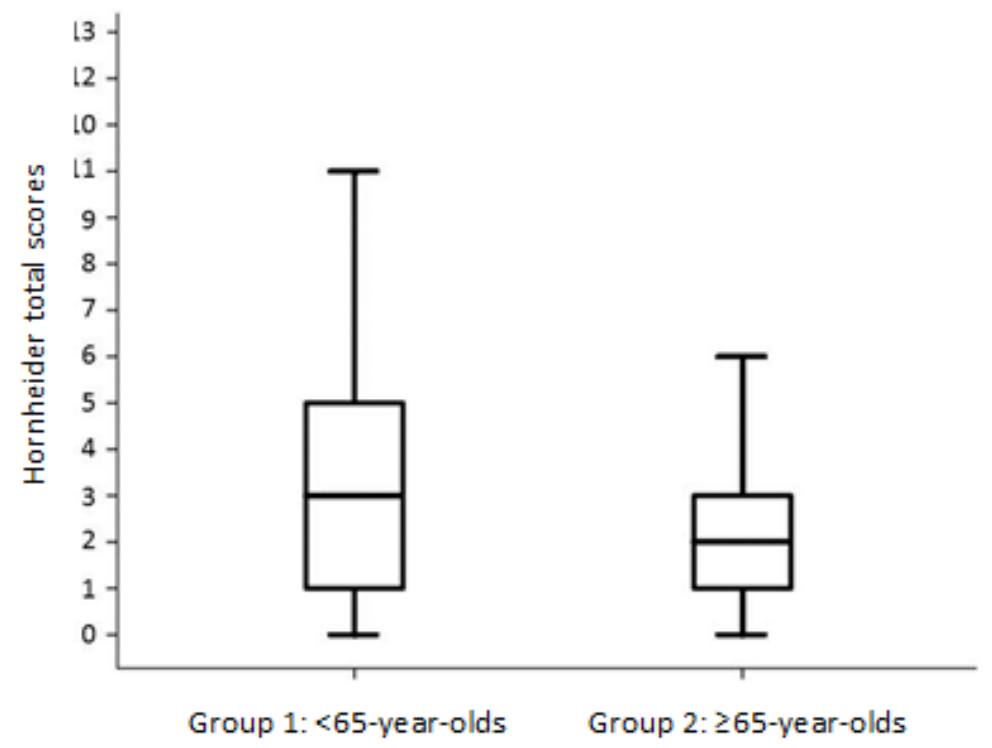

Figure 4. Psycho-oncological need for care by $<65$ year-old (younger) and by $\geq 65$ year-old (older) patients

\section{Influence of Age}

We could observe a significant difference $(\mathrm{p}=0,02)$ in the need of care of $<65$ year-olds $(62,2 \%)$ in contrast to $\geq 65$ year-olds (37,5\%).

Table 3. Tumor Entities of Study Participants with HH-Score $\geq 4$

\begin{tabular}{|c|c|c|}
\hline $\begin{array}{c}\text { Study Participants } \\
\text { (HH-Score } \geq \mathbf{4})\end{array}$ & $\begin{array}{c}\text { Age Group 1 } \\
\text { „<65“(n=31) }\end{array}$ & $\begin{array}{c}\text { Age Group 2 } \\
, \geq \mathbf{6 5} \text { “(n=16) }\end{array}$ \\
\hline Men (\%) & 29,8 & 12,8 \\
\hline Women (\%) & 36,2 & 21,2 \\
Gastrointestinal Tumors (\%) & 21,3 & 2,1 \\
\hline Haemato-oncolog. Tumors (\%) & 12,8 & 17 \\
\hline Mamma Tumors (\%) & 17 & 6,4 \\
\hline Other Tumors (\%) & 10,6 & 18,8 \\
\hline
\end{tabular}




\section{Tumor Entities}

We divided the tumor entities in four groups: gastrointestinal tumors, haemato-oncological tumors, mamma carcinoma und other tumors. Gastrointestinal tumors were significantly more common in men ( $<<0,001,33,8 \%)$ than in women $(9,9 \%)$ and haemato-oncological tumors were also significantly more common in men ( $\mathrm{p}=0,002,44,1 \%)$ than in women (21\%). Mamma carcinomas naturally showed in women $(\mathrm{p}=0,001)$. In other tumors no gender associations could be made. These results are depicted in figure 5.

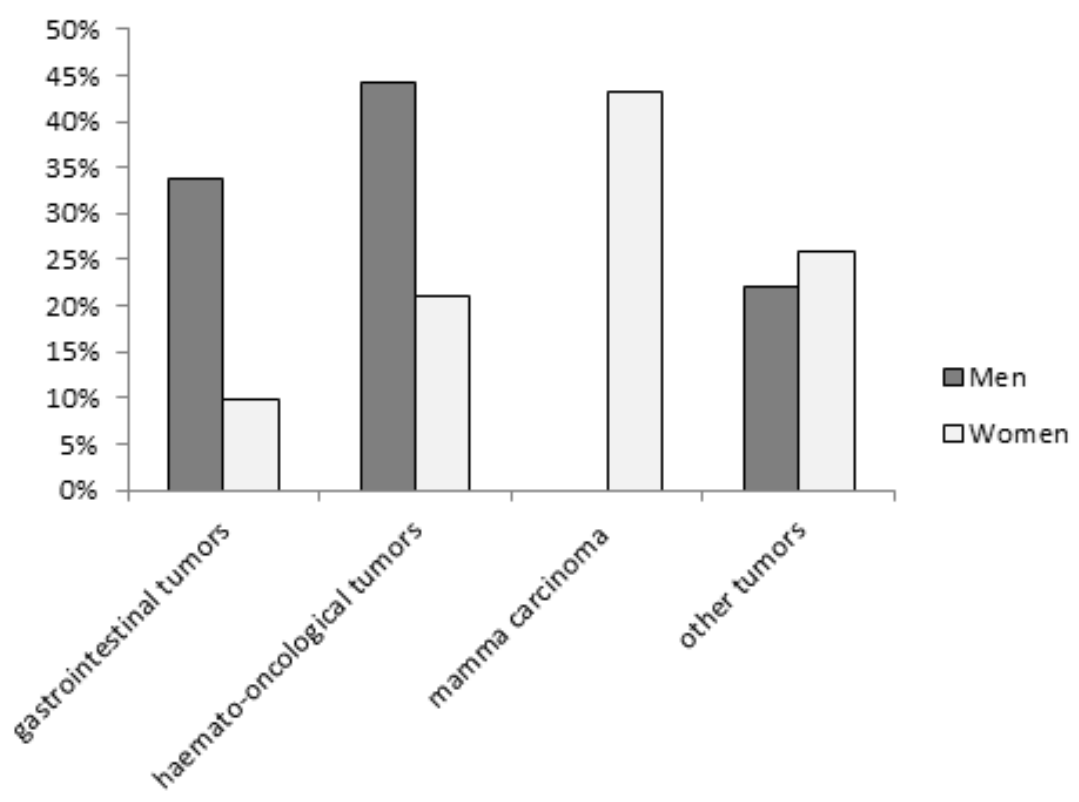

Figure 5. Tumor Entities of all Study Participants factoring in Gender.

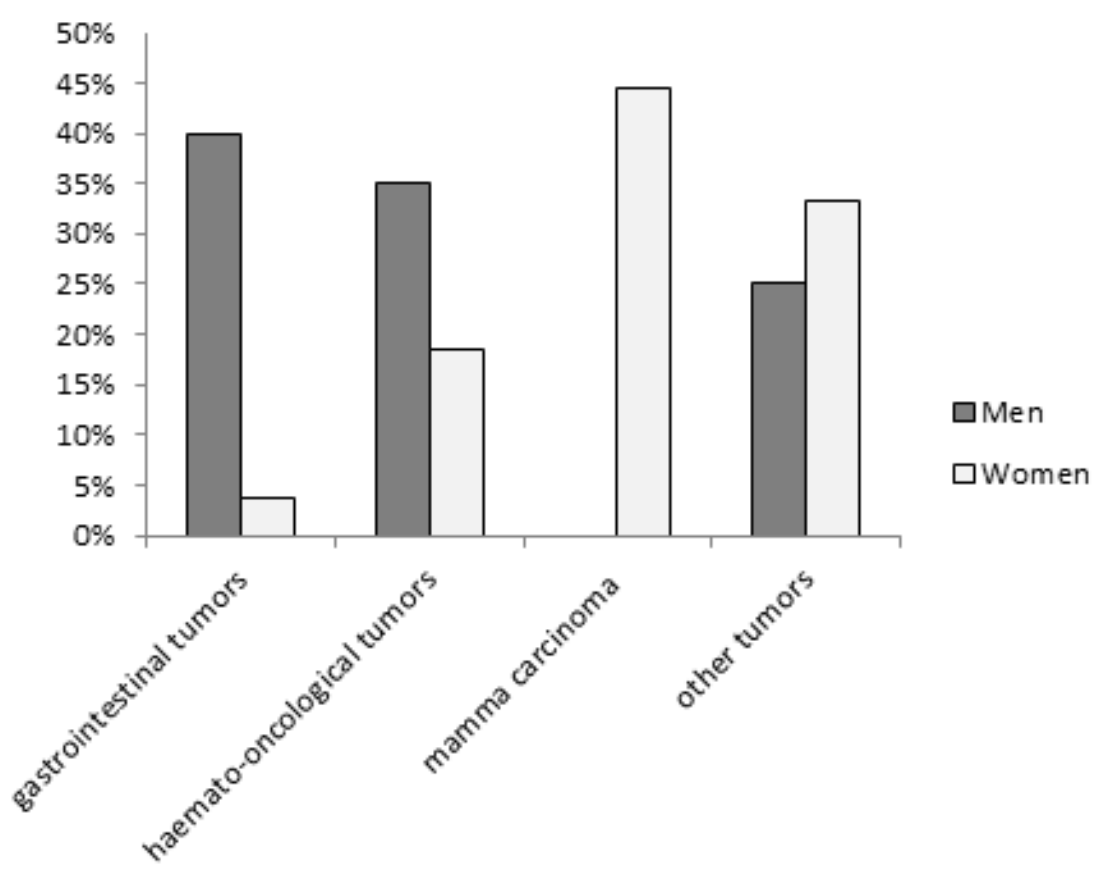

Figure 6. Tumor Entities of Study Participants with HH-Score $\geq 4$ factoring in Gender. 


\section{Discussion}

This study proves, in accordance with current research $[13,15]$, that, overall, a third of patients with a tumor disease are in need of psycho-oncological and psychosocial care.

Additionally, for the first time it should be noted that this demand is especially high in younger patients; accounting for two thirds in the age group $<65$ years.

This shows that psycho-oncological intervention is a crucial service in the support of patients in their pathological process and accompanying therapy.

Compared to existing specialist literature and diverse publications a screening method would be prudent. However, it is still not utilized regularly in the clinical routine and comparisons of different screening methods are often difficult due to the often severely varying study design.

The psychological experience of stress and life-threatening problems are often not noticeable prima facie. Many affected patients are hardly ever addressed upon this topic and there are still no standardized screening methods. Thus, it is often the case that severely strained patients are "overlooked" and do not receive psycho-oncological support.

One of the strengths of this pilot-study is that we consecutively collected the patients data and did not differentiate between outpatient, day-unit or inpatient patients, which explains the patient collective's heterogeneity. We also did not distinguish whether patients were adjuvant and/ or in palliative care undergoing chemotherapy. Patients were addressed non-selectively and well characterized factoring in age, gender and tumor entity.

Its limitations are that the number of cases was relatively small regarding the annual treatment of cancer patients (over 800 per year alone in this ward) and that we only collected monocentric data.

Patients are in an exceptional psychological state, especially during the first weeks after receiving the diagnosis. They are confronted with an enormous amount of information concerning disease, therapy and prognosis, which they have to process and cope with.

Early detection of stressed patients and referral to a psycho-oncologist results in an improved satisfaction with treatment. Quality of life, a positive influence on survival and more efficient treatment possibilities have been documented [24-26]. Furthermore, savings in expenses for the healthcare sector were noted [27]. Fewer patients suffer from severe psychological disorders. They are less scared during phone conversations and consultations [28]; the communication between treatment team and patient improves. The strain and the burn-out risk in the oncological team demonstrably decreases [7].

\section{Prospect for Future Research}

Consequently every psycho-oncological patient should receive psycho-oncological support suitably to their tumor.
According to professional opinions [29] there is still a big need for development in psycho-oncology regarding structural quality (personnel, qualification), process quality (instruments, guidelines) as well as quality of results (evaluation). For these reasons we need an improvement of the existing medical care supply.

\section{Conclusions}

Concluding, this study shows that the Hornheider-Screening is a very easy, quick and effective paper-pencil-test. It is used for screening to record the psycho-oncological/ psycho-social need for care. It can be issued by physicians, psycho-oncologists and caregivers. Patients generally responded well to the survey. This method is most appropriate for psycho-oncological indication-diagnostics in clinical routine.

By request of any given oncological patient a quick and efficient diagnosis can be provided, in order to evaluate the need for care and organize respective treatments.

\section{REFERENCES}

[1] Österreichisches Krebsregister, Statistik Austria, letzte Korrektur 28.01.2016.

[2] Vehling S., Koch U., Ladehoff N. et al. (2012) Prävalenz affektiver und Angststörungen bei Krebs: Systematischer Literaturreview und Metaanalyse. Psychother Psych Med 62: 249-258.

[3] Schäffeler N., Enck P., Riessen I. et al. (2010) Screening psychischer Belastungen und Erhebung des Wunsches nach psychosozialen Unterstützungsangeboten bei Patientinnen mit Manmmakarzinom. Psychosom Med Psyc 56: 207-219.

[4] Koch A., Gaser E., Meissner W., Wedding U. (2010) Indikatoren und Korrelate des psychoonkologischen Betreuungsbedarfs in der Palliativmedizin, Palliativmedizin; $11-\mathrm{P} 144$.

[5] Mehnert A., Lehmann C., Cao P., Koch U. (2006) Die Erfassung psychosozialer Belastungen und Ressourcen in der Onkologie - Ein Literaturüberblick zu Screeningmethoden und Entwicklungstrends. Psychother Psych Med 56: 462-479.

[6] Zabora J.R. (1998) Screening procedures for psychosocial distress. In: Holland J.C. (Hrsg.) Psycho-oncology. Oxford University Press, New York, Oxford, S. 653-661.

[7] Holland J.C. (2002) History of Psycho-Oncology: Overcoming attitudinal and conceptual barriers, Psychosomatic Medicine 64 (2): 206-221.

[8] Reuter K. (2010) Psycho-oncology: utility, principles and therapeutic options. Psychother Psychosom Med Psychol 60 (12): 486-497.

[9] Strittmatter G. (2006) Screening-Instrumente zur Ermittlung der Betreuungsbedürftigkeit von Tumorpatienten. In: Herschbach P, Heußner P, Sellschopp A (Hrsg.) 
Psycho-Onkologie - Perspektiven heute. Pabst, Lengerich, Berlin (u.a.), S. 122-142.

[10] Senf B., Kaiser J. (2013) Krankheit: Lernen im Ausnahmezustand?, pp 398-398 Brustkrebs als Auslöser von psychosozialen Belastungen, Angst und Depression sowie Angebote, Methoden und Effekte psychoonkologischer Interventionen.

[11] Söllner W., König A., Schiessling G. et al. (2004) Providing psychosocial support for breast cancer patients based on screening for distress within a consultation-liaison service. Psycho-Oncol 13: 893-897.

[12] Rosenberger C., Höcker A., Cartus M. et al. (2012) Angehörige und Patienten in der ambulanten psychoonkologischen Versorgung: Zugangswege, psychische Belastungen und Unterstützungsbedürfnisse. Psychother Psych Med; 62: 185-194.

[13] Sperner-Unterweger B. (2011) Psycho-oncology psychosocial oncology: Integration in a concept of oncological treatment. Nervenarzt 82 (3): 371-380.

[14] Kusch M., Labouvie H., Hein-Nau B. (2013) Klinische Psychoonkologie, Springer Verlag Berlin, Heidelberg.

[15] Faller H., Schuler M., Richard M. et al. (2013) Effects of psycho-oncologic interventions on emotional distress and quality of life in adult patients with cancer: a systematic review and meta-analysis. J. Clin Oncol 31: 782-793.

[16] Herschbach P., Weis J. (2010) Screeningverfahren in der Psychoonkologie. Testinstrumente zur Identifikation betreuungsbedürftiger Krebspatienten. Eine Empfehlung der PSO für die psychoonkologischen Behandlungspraxis; Berlin, 2. Auflage, DGK Krebsgesellschaft.

[17] Sommerfeldt S., Ihrig A., Brechtel A. et al. (2007) Psychoonkologisches Screening in der Routineversorgung. Psychosomatik und Konsiliarpsychiatrie 1: 293-297.

[18] de Zwaan M., Mösch P., Sinzinger H. et al. (2012) Der Zusammenhang zwischen psychoonkologischem Betreuungsbedarf, Wunsch nach Unterstützung und tatsächlicher Behandlung bei Krebspatientinnen und -patienten, Neuropsychiatrie 26: 152-158.

[19] Wetzel C., Krempl A., Allgayer A. et al. (2011) Psychische Belastung und Wunsch nach psychoonkologischer Unterstützung bei Brustkrebs während stationärer und ambulanter Behandlung. Senologie - Zeitschrift für Mammadiagnostik und -therapie, 8-A211.
[20] Miovic M., Block S. (2007) Psychiatric disorders in advanced cancer. Cancer 110: 1665-1676.

[21] Rumpold C., Augustin M., Zschoke I. et al. (2001) Die Validität des Hornheider Fragebogen zur sozialen Unterstützung bei Tumorpatienten. Psychther Psych Med 51: 25-33.

[22] Strittmatter G. (1997) Indikation zur Intervention in der Psychoonkologie: Psychosoziale Belastungen und Ermittlung der Betreuungsbedürftigkeit stationärer Hauttumorpatienten. Waxmann, Münster.

[23] Bundesgesundheitsblatt (2011) Psychische Komorbidität bei Krebserkrankung von Prof. J. Weiss, A. Boehncke, Volume 54 (1), pp 46-51.

[24] Kuchler, Thomas; Bestmann, Beate; Rappat, Stefanie; Henne-Bruns, Doris und Wood-Dauphinee, Sharon (2007): Impact of Psychotherapeutic Support for Patients with Gastrointestinal Cancer Undergoing Surgery: 10-Year Survival Results of a Randomized Trial, Journal of Clinical Oncology 25 [19], Seite 2702-2708. URL: http://jco.ascopubs.org/cgi/content/abstract/25/19/2702

[25] Newell, Sallie Anne; Sanson-Fisher, Rob William und Savolainen, Nina Johanna (2002): Systematic Review of Psychological Therapies for Cancer Patients: Overview and Recommendations for Future Research, Journal of the National Cancer Institute 94 [8]: 558-584. URL: http://jnci.oxfordjournals.org/cgi/content/abstract/jnci;94/8/55

[26] Leon-Pizzaro C, Gich I, Barthe E et al. (2007) A randomized trial of the effect of training in relaxation and guided imagery techniques in improving psychological and quality of life indices for gynaelogic and breast brachytherapy patients. Psycho Oncology 16(11): 971-979

[27] Strong, V; Waters, R; Hibberd, C; Murray, G; Wall, L; Walker, J; McHugh, G; Walker, A und Sharpe, M (2008): Management of depression for people with cancer : a randomised trial., The Lancet 372 [5], page 40-48

[28] Waadt S, Duran G, Berg P, Herschbach P (2011) Progredienzangst. Manual zur Behandlung von Zukunftsängsten bei chronisch Kranken, Schattauer, Stuttgart, Deutschland

[29] Schumacher A, (2004) Stellenwert der Psychoonkologie im deutschen Gesundheitssystem. Der Onkologe (Supp.2) 10: 598-5102. 